\title{
Midline Shift
}

National Cancer Institute

\section{Source}

National Cancer Institute. Midline Shift. NCI Thesaurus. Code C125179.

A radiologic finding that describes the movement of the brain beyond the center line. 